\title{
Triple helix approaches and social network perspectives
}

\author{
Yeon-Ok Lee ${ }^{1} \cdot$ Han Woo Park
}

Published online: 4 June 2015

(C) Springer Science+Business Media Dordrecht 2015

This special issue celebrates the inaugural Daegu Gyeongbuk International Social Network Conference (DISC) held in 2013 by the Asia Triple Helix Society in conjunction with the City of Daegu, South Korea (http://asia-triplehelix.org/DISC2013). Under the title of 'Knowledge Network Analysis in the Emerging Big Data Research', the event welcomed more than 150 attendees from around the world, including distinguished scholars in the field of Triple Helix, and provided a space for discussion on the following topics:

- Applying webometrics, scientometrics, and informetrics to the structure of knowledge

- Collaboration and network economics

- Education research from the perspective of social networks

- Knowledge sharing among university, industry, and government

- Mapping and visualizing knowledge networks

- Measuring collaboration using social network analysis

- Media and communication network studies using big data

- Network applications in humanities and social sciences

- Network characteristics of R\&D in Asian countries

- Public policies in the domain of big data research

- Sociocultural issues in big data research

- Technology marketing using big data-driven network analysis.

Han Woo Park

hanpark@ynu.ac.uk

Yeon-Ok Lee

yl22@soas.ac.uk

1 Doctoral School, SOAS, University of London, London, UK

2 Department of Communication \& Information, Interdisciplinary Program of East Asian Cultural Studies, Interdisciplinary Program of Digital Convergence Business, Yeungnam University, Gyeongsan, Korea 
This issue contains 11 papers, which have been carefully selected and peer-reviewed to represent the rich discussion that took place at the event for the benefit of a broader community. (Any paper co-authored by the guest editor has been handled separately by the Editor-in-Chief of the journal to ensure objectivity.)

In 2015, the Asia Triple Helix Society was expanded and renamed the World Association for Triple Helix and Future Strategy Studies. Readers interested in further details of DISC 2013 might like to refer to the slides of the keynote speeches at http://www. slideshare.net/hanpark/disc2013-keynote-speaker. The April/May 2014 edition of the Journal of Contemporary Eastern Asia (Volume 13, Number 1) was also born out of the conference, available at http://www.jcea-online.net. 